\title{
Correction to: Landscape Metrics Integrated in Hydraulic Modeling for River Restoration Planning
}

\author{
Paolo Tamagnone ${ }^{1} \cdot$ Elena Comino ${ }^{1} \cdot$ Maurizio Rosso $^{1}$
}

Published online: 17 March 2020

(C) Springer Nature Switzerland AG 2020

\section{Correction to: Environ Model Assess https://doi.org/10.1007/s10666-020-09693-y}

The original version of this paper was unfortunately published with an error.

The online visualization of the paper is correct; instead, the printed version (page 5) reports strange lines into the vectors of Eq. (2), and the $\mathrm{G}$ is divided from its expression (see Fig. 1).

The online version of the original article can be found at https://doi.org/ 10.1007/s10666-020-09693-y

\footnotetext{
Paolo Tamagnone

paolo.tamagnone@polito.it

1 Department of Environment, Land and Infrastructure Engineering, Politecnico di Torino, Corso Duca degli Abruzzi 24,

10129 Turin, Italy
} 
Fig. 1 A online visualization (https://link.springer.com/article/ 10.1007/s10666-020-09693-y), (B) visualization of the printed version

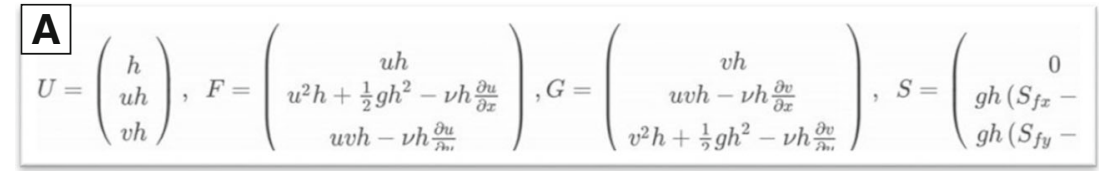

$\mathbf{B}=\left(\begin{array}{c}h \\ u h \\ v h\end{array}\right), F=\left(\begin{array}{c}u h \\ u^{2} h+\frac{1}{2} g h^{2}-\nu h \frac{\partial u}{\partial x} \\ u v h-\nu h \frac{\partial u}{\partial y} \\ v h \\ u v h-\nu h \frac{\partial v}{\partial x} \\ 11 \\ v^{2} h+\frac{\partial}{2} g h^{2}-\nu h \frac{\partial v}{\partial y} \\ \quad S= \\ g h\left(S_{f x}-S_{B x}\right) \\ g h\left(S_{f y}-S_{B y}\right)\end{array}\right)$
$\left(\begin{array}{c}0 \\ \end{array}\right)$

Publisher's Note Springer Nature remains neutral with regard to jurisdictional claims in published maps and institutional affiliations. 